\title{
Study on The Catcher in the Rye from the perspective of Jewish culture
}

\author{
Caiyun Zhang \\ Foreign language School, Yan'an University, Yanan Shaanxi, 716000, China
}

\author{
Keywords: Jewish culture, Catcher in the Rye, Salinger
}

\begin{abstract}
The Catcher in the Rye is the representative work of the famous American Jewish writer Salinger. The sculpture of the personality of the protagonist Holden based on Jewish culture clarifies the relationship between the subject and the Jewish culture and shows that Salinger carries forward the excellent traditional culture of Jewish people and has a certain research value. With the basis of the domestic study on The Catcher in the Rye, this paper deeply analyzes the text from the perspective of Jewish culture hoping to provide some support for the further development of related researches.
\end{abstract}

\section{Introduction}

David - Salinger is a famous American Jewish writer. The difference of his point of view on Jewish issues from that of other contemporary writers is in that Salinger is affected by American society to a certain degree and his works have a strong representativeness and the sculpture of the protagonist is also personalized. The Catcher in the Rye mainly tells the story in which the hero Holden is expelled from the school and strayed in New York area to find his spiritual home. This work reflects the interpretation on the spiritual world of the teenagers under the pressure form society and the confusion for self existence and the wander sense of spiritual world. Through the first-person narrative, the work brings the readers into the hero's inner world, and makes them experience the prosperous living scenes of the American society of that time with the hero. This makes readers feel the rich historical sediment of Jewish culture. The Jewish identity of Holden is not clarified in the novel, while the permeation of the Jewish culture reflects the drifting history and the confused spiritual process of the Jewish people with rich connotation.

\section{The domestic study on the Catcher in the Rye}

China formally started the study on Salinger's works from 1980s but the study range was relatively narrow and the depth was not enough. In recent years, with the further development of the publishing industry and researches at home and abroad, the study on the Catcher in the Rye is increasing and has got corresponding results. Domestic researchers mainly study this work from the perspective of creation subject consciousness, the acceptance reflection of the reader, the rhetoric art of the text and the cultural and historical context. The entry point of this paper belongs to the creative consciousness of the author and the narrative subject of the text. The Catcher in the Rye was published in the middle of last century. Under the social background of that time, researchers of related aspects treated this work as a mirror of the reality and used it to analyze the reality and made the holder of this mirror Holden as the key point for the analysis and made deeper analysis on the sculpture of his personality. For example, the domestic scholar Zhang Guixia divides Holden's image clearly. She values Holden as the awakened one from the agony and the rebelled one for American society. He expresses the loner's image in western literature and the watch man's image for the chase for spiritual homeland ${ }^{[1]}$. In the aspect of the protagonist's character, the domestic scholars also spend a lot of energy on mixing Freud's psychoanalysis, Jung's archetypal criticism, Lacan's post structural psychology, and Fromm's humanistic psychology with the sculpture of the protagonist of the Catcher in the Rye and have achieved some results. The researches on the theme are also obvious. The related researches on the edged man or the conflicts between modern civilization and traditional Jewish civilization are in depth and have the significance of reference. This paper takes the perspective of Jewish culture as the entry point and analyzes the text of the Catcher in the Rye and provides corresponding support and reference for further studies. 


\section{The interpretation on the Catcher in the Rye from the perspective of Jewish culture}

The spiritual drift. The Jewish nation has a long history of drifting culture, and the ultimate goal of wandering is to find its own spiritual home in constant exploration. As described in the Bible, God said to the ancestor of Jewish nation Abraham: You shall leave this place, this nation and your father's place to the place where I point to. When Holden was expelled from the school he found and discovered new life in the modern city. This reflects the inheritance and development of the Jewish drifting culture. Holden comes from a middle class family which is relatively rich. His mother lost her mental sanity after his younger brother's death and his father is engaged in business and rarely has time to educate Holden which weakens the father-and-son relationship. This makes a sense of loneliness since Holden's juvenile age that can not be eliminated thus he can not position himself in society and has a low sense for self identity. In the surface he has abandoned the Jewish tradition which values the bloodline of family. He can not recognize anything in Pansy Middle School and has a sense of rejection. So in his daily life he wears bizarre clothes with swears all the time and he always felt alone and can not be understood by society ${ }^{[2]}$. After he was expelled from school, he was not wiling to come back home for shelter. All he can do is to find the meaning of life in society. In the modern society of New York, he appears on the bars and clubs with superficial prosperity to drain the agony. He gradually sees the ugly realties in the city and the selfishness of human, which makes him more eager to return to the spiritual peace. From the analysis above we can see that the drift of Holden is the self abandon of independent personality. The suffering is from spiritual level so the process of his drift is the process for self liberation. The drift of Holden is to get apart from the darkness, hypocrisy and anomic behaviors of society in the beginning and fight back without a clarified objective for spiritual pursuing. But when he experienced a series of dark reality, when he saw children walking by the dangerous road singing "if someone catches the ones in the rye" he suddenly realized that the wonderful ideal spiritual world lies in the simple world of children, so he wants to guard this spiritual habitat whimsically to protect children's mind from the contamination of adults. At this time the spiritual world of protagonist gets revived in a certain way and his spiritual drift turns into reasonable level form the original sensitive level, which deepens the theme of this work.

The analysis on the edged man. Affected by the historical reality, Jewish people live in the cracks of alien culture society for a long time. They put themselves outside the value system of this alien society through the unique habits, the spacial wandering and the indulgence and become the edged man that can not make self identified in alien society. Dickstein interprets the image of edged man and he thinks that actually the edged man is totally isolated from the realistic world. And they prison themselves in the superiority complex of self anxiety through self alienation. When entered in the post modern society, the sense of edge and loneliness of individuals will get intensified and the edged man will show his rebellious living status to society under the non-reasonable living status. In the Catcher in the Rye, the family of Holden can not give his the sense of belonging while Pansy Middle School is not the image built by his self consciousness and filled with the darkness of adult society which hits his mind and he can not blend in it. So he has to express dissatisfaction with rebellious behaviors. The protagonist Holden derides the traditional social morality and he praises highly to find personality freedom and liberation of society in the new era. So he fights back in unique decadency. Holden likes wearing a red hat in an opposite way and he swears all the time and hates to study and appears in the bars and night clubs. He smokes, drinks and even call the prostitutes. To survive from this dark modern society independently, telling lies has become his living habit. Holden lives a decadent life live modern people but he hates the decadency of the adult world. He asks the driver where the ducks of the central park spend the winter. This reflects the truth that he can not find a way in society and shows the spiritual crisis of Jewish teenager in modern city life. "You can never find a nice and quiet place because it doesn't exist.” In Holden's cognition, even if you find an ideal spiritual habitat, when you arrive, people from another world will sneak in and you will lose this habitat again. Due to the self pursuing on the sentimental level, Holden prefers not to enter adult world thus he refuses to grow up and he hopes to escape the pressure from society and trust the lost rurality on the ideal spirit. This shows his indefinite worship to sentimental ego. But we should realize that this extreme pursue after the individual value doesn't make Holden get into the ideal spiritual 
habitat - the rye eventually. On the contrary, he was treated as a lunatic by the main steam of society. This reveals the compression to the freedom of humanism by the main steam of society. The spiritual pursing of the edged man can not be realized in the realistic society and even a sense of anxiety that can not be drained would emerge which has a bad influence on the spiritual life. It reflects the spiritual crisis of the edged man in modern society. ${ }^{[3]}$

\section{Sacrifice and Redemption}

In Jewish history and culture construction, sacrifice generally contains two levels of meaning. Its original meaning is the sacrificed animals or human for the great sacrifice of the Lord. With the development of the time, the meaning of sacrifice is also gradually expanded and extended. To a certain extent, it especially refers to give up some of self interests and even life to accomplish more value and significance. At the same time, under the influence of religious thought, Jews believe that redemption is a practice done by social individual to real life. They can't let the idea of atonement stay at the spiritual level, and they also do not think sacrifice can complete the redemption ${ }^{[4]}$. In real life, in the process of spiritual construction, with constant sacrifice and self-salvation the Jews get spiritual renewal, which shows the profound comprehension and interpretation to the life. And Jewish writers put these ideas into the work, which has a certain influence on the human reflection of the modern society. Facing today's materialistic society and the empty, hopeless mental state, Salinger found the path of self-salvation in the work. That is to protect young people's spiritual growth.

In "The Catcher in The Rye," the hero despaired with the current education system and his wandering life in New York City makes him experience the darkness of society. He realized that the truth, kindness and beauty of adult world were losing with the drive of the materialized world. What remained were the selfishness and ugliness of human nature. He even got a sick thought when he was desperate: Maybe what I really want to do is to commit suicide. I feel like jumping from the windows ${ }^{[5]}$. When he was pushed to the state that he lost himself and his spiritual world was going to collapse by the dark realistic society, he found the simple and wonderful world of children and took it as his spiritual habitat. He actually found a way of self redemption and a way to protect children's mind. The plot that Holden admires his dead brother who was more popular, and the plot that he though chatting with his sister was the happiest thing in the word reflect that his pursuing for the simple and wonderful children world. Especially when he played seesaw with a child a heavy rain gave him epiphany on the spiritual level, which made him get real freedom and liberation and he found his ideal spiritual world eventually. Hereby the epiphany from the heavy rain is the metaphor of the baptism ceremony in Jewish religion. The rain gave him liberation and rushed the misdeeds in his past. This reflects his new life. Even though he failed to resist against society and was treated as a lunatic. But in this process he got the spiritual comfort and actually experienced the return of spirit. From this we can see that Salinger seems to prove that only with the spiritual world of children can the edged man get the spiritual redemption and self liberation and survive in the society through the Catcher in the Rye.

\section{Conclusion}

In a word, the personalized protagonist sculpting method of Salinger in "The Catcher in The Rye" expresses the unique Jewish culture complex. To a certain extent, it reflects the though will of Jews in the realistic society to pursue self and explore the essence of life. For the shaping of the characters of Holden, and his the anxiety in the modern society and alienation phenomenon reveal the crisis and predicament for survival and development of the Jews in the alien society and shows the fusion and the conflict of Jewish culture and world culture and society which deepens the theme of the text and has certain research value. 


\section{References}

[1] Li Xiujuan. The study on the cultural theme in "The Catcher in The Rye". Shanghai Normal University, 2012.

[2] Gao Jin. The Jewish culture connotation in "The Catcher in The Rye". Journal of Qiqihar University (Philosophy and social sciences edition), 2015 (4) : 108-109.

[3] Ning Yunzhong. The obscure Jewishness in "The Catcher in The Rye". Journal of East China Jiaotong University, 2010, 27 (4) : 92-95.

[4] Li Xiujuan, Liu Juan. The eternal watcher - study on the "sacrifice and redemption" of Holden. Journal of Northern Literature, 2015 (5) : 64-64.

[5] Tian Yingchun. The foreign research review of "The Catcher in The Rye". Journal of Lanzhou University (social science edition), 2014, and (2) : 152-155. 